\title{
Phase shifts and stable states on coral reefs
}

\author{
Steve R. Dudgeon ${ }^{1, *}$, Richard B. Aronson ${ }^{2}$, John F. Bruno ${ }^{3}$, William F. Precht ${ }^{4}$ \\ ${ }^{1}$ Department of Biology, California State University Northridge, Northridge, California 91330, USA \\ ${ }^{2}$ Department of Biological Sciences, Florida Institute of Technology, 150 West University Boulevard, Melbourne, \\ Florida 32901, USA
}

${ }^{3}$ Department of Marine Sciences, The University of North Carolina at Chapel Hill, Chapel Hill, North Carolina 27599, USA

${ }^{4}$ Florida Keys National Marine Sanctuary, NOAA, PO Box 1083, Key Largo, Florida 33037, USA

\begin{abstract}
Recent transitions from coral to macroalgal dominance on some tropical reefs have engendered debate about their causes and effects. A widely accepted view is that reef environments support stable, alternative coral or non-coral assemblages, despite the lack of evidence to support this hypothesis. Confusion in the literature stems from (1) misunderstanding theory; and (2) conflating a switch between alternative stable states with a shift in the phase portrait of a single equilibrial system caused by a persistent change, or trend, in the environment. In the present paper we outline the conceptual derivation of the hypothesis of alternative stable states, distinguish it from the phase-shift hypothesis, and discuss the evidence required to support each one. For cases in which firm conclusions can be drawn, data from fossil and modern reefs overwhelmingly support the phase-shift hypothesis rather than the hypothesis of alternative stable states. On tropical reefs, a given environment evidently supports at most a single stable community. Corals dominate environments that are disturbed primarily by natural events and have small anthropogenic impacts. In such environments, macroalgae dominate a stage during some successional trajectories to the stable, coral-dominated community. In anthropogenically perturbed environments, the resilience of the coral-dominated community is lost, precipitating phase shifts to communities dominated by macroalgae or other noncoral taxa. The implication for reef management and restoration is both substantial and optimistic. To the extent that the environments of degraded reefs are restored, either passively or actively, the communities should return to coral dominance.
\end{abstract}

KEY WORDS: Alternative stable states - Community state - Coral · Coral reef · Macroalgae • Multiple stable states $\cdot$ Phase shift

\section{INTRODUCTION}

The idea that coral reefs switch between stable, alternative community states of coral and macroalgal dominance is one of the most widely accepted concepts in the coral reef literature (Knowlton 1992, 2004, Nyström et al. 2000, Scheffer et al. 2001, Elmqvist et al. 2003, Scheffer \& Carpenter 2003, Bellwood et al. 2004, Mumby et al. 2007a, Elmhirst et al. 2009, Mumby 2009, Norström et al. 2009, Riegl et al. 2009, but see Knowlton 2006). This model of the behavior of reef assemblages has attained the status of a paradigm (sensu lato) among coral reef ecologists (see Graham \& Dayton 2002). Despite its ubiquity, attractiveness, and nearly universal acceptance, there is little to no empirical evidence supporting the argument that reefs in general are dominated at a given time by 1 of 2 or more alternative stable states.

Much of the confusion stems from a misunderstanding of the conceptual underpinnings of the stablestates hypothesis and the evidence needed to demonstrate that a state, which is a particular configuration or composition of a reef community, is in fact stable. Reef scientists regularly conflate movement between stable states with phase shifts, although the 2 concepts are very different. A phase shift or regime shift is a change in the equilibrial community in response to a persistent change in environmental conditions. Phase shifts are 
often characterized by dominant populations of an ecological community responding smoothly and continuously along an environmental gradient until a threshold is reached, shifting the community to a new dominant or suite of dominants (Done 1992). In any given environment, there is at most one stable state. 'Alternative stable states,' in contrast, means that $>1$ configuration of the biological community, i.e. more than one state, can occur in the same place and under the same environmental conditions at different times. If any such configuration can persist under a wide range of environmental conditions, then it will appear to be ecologically locked, i.e. it will resist conversion to a different state.

Confusion in the coral reef literature about phase shifts and alternative stable states is not surprising, because scientists have been confusing and redefining stable states since the idea was formally introduced by Lewontin (1969). With very few exceptions (e.g. Fong et al. 2006), studies of coral reefs either fail to recognize the intellectual precedent established by the early works that shaped the theory or do not persuasively justify their redefinition of key concepts. Rigorous and fixed definitions of stable states, phase shifts, and related concepts are essential if they are to have any utility for describing nature.

In a recent review, Petraitis \& Dudgeon (2004) discussed the criteria for rigorous experimental tests of alternative stable states. In this paper, we focus on how and why theory dictates those criteria by outlining the derivation of the concept of alternative stable states. We define and discuss related phenomena such as phase shifts, hysteresis, and resilience. We then evaluate the evidence for stable states and phase shifts in the coral reef literature. Finally, we consider the broad implications for reef management and restoration of incorrectly assuming that alternative stable states are common or ubiquitous.

\section{A PRIMER OF PHASE SHIFTS AND ALTERNATIVE STABLE STATES}

\section{Characterizing community dynamics}

Graphical abstractions that describe the dynamics of multispecies assemblages are called phase portraits (e.g. Lotka-Volterra predator-prey or competition models [Lotka 1956]; Emlen 1977, Ricklefs 1979). Phase portraits depict the collection of all possible successional trajectories leading to one or more equilibria for a given environment. The phase portraits are derived from curves in the plane that are observed by viewing a time series straight down the time axis from a height corresponding to a large value of time, $t$ (Abraham \&
Shaw 1992). The state of an $n$-species community can be represented at any time $t$ by the point in $n$-dimensional space corresponding to the abundance of each taxon (Levins 1968, Lewontin 1969), which ecologists collapse into an aggregate metric of 1 to 3 dimensions using multivariate analysis to visualize changes of state (Petraitis \& Dudgeon 2005, Petraitis et al. 2009). Fig. 1A shows one possible time series of community states described in 2 dimensions, and Fig. 1B is a phase plot of the corresponding successional trajectory. Fig. 1C depicts the complete phase portrait of the community for a given environment. (Note that Fig. 1C depicts a plane and a stable point only for heuristic simplicity. The surface may exhibit great complexity. Likewise, the equilibrial state of the system need not show such simple behavior as remaining constant through time; rather, our arguments apply whether the successional end-states are represented in phase space by points, limit cycles, or other behaviors.)

It is worthwhile to delineate what a phase portrait implies in terms that are meaningful to community ecologists, in order to define and distinguish phase shifts and multiple stable states. First, the phase space
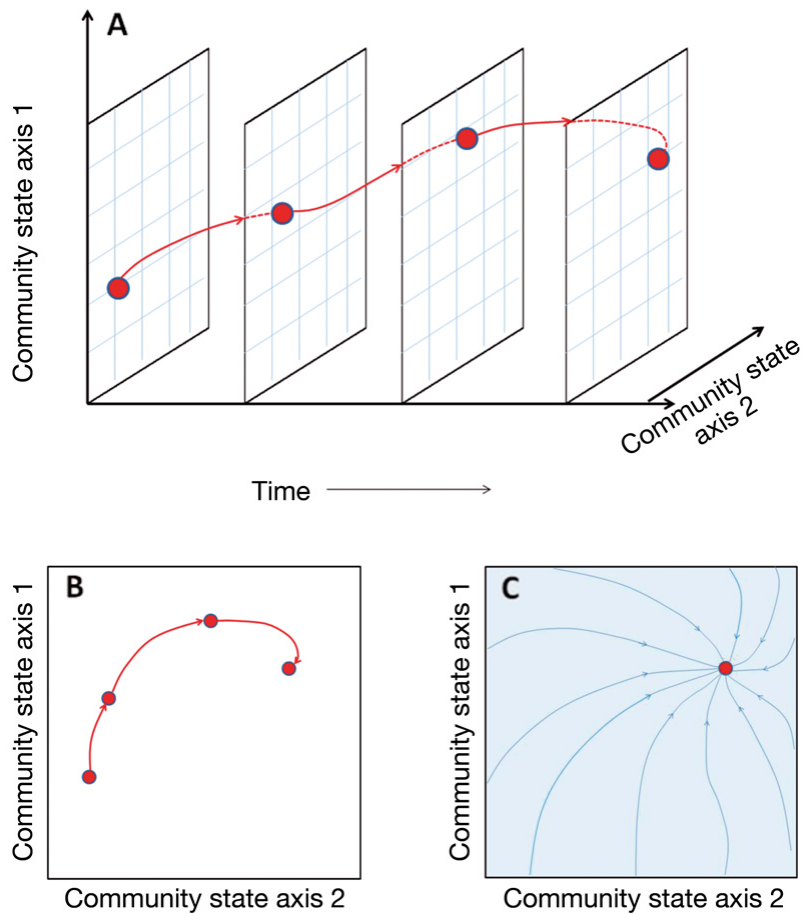

Fig. 1. Community development of a system with a single equilibrial state. (A) Time series of changes in community state plotted in 2 dimensions. (B) Phase plot of successional trajectory of the community shown in the time series in panel (A). (C) Phase portrait showing successional trajectories from any point in the state space towards the attractor. Red symbols: community state sampled at points in time in panels (A) and (B), and the point of equilibrium in panel (C); arrows: trajectories of succession. Modified from Abraham \& Shaw (1992) 
(the 2-dimensional plane in Fig. 1B,C) represents a specific set of physico-chemical environmental conditions in which the $n$ species interact. We define the environment based on Schröder et al. (2005), who followed Peterson (1984). The environment is the set of extrinsic parameters that influence community dynamics but are not in turn affected by these community dynamics. Factors that are dynamically coupled to the community are part of that system and are by definition not part of the extrinsic environment. As Peterson (1984) recognized, there are potential difficulties in distinguishing historical, biotically driven environmental conditions from extrinsic ones, and in some instances they may seem inextricably linked. Essentially, parameters that are either only weakly or not at all affected by the system are considered part of the environment (Schröder et al. 2005).

We offer some examples to clarify this difficult but critical distinction. State variables, such as species abundances, the interactions between them, and their impacts on the local environment (e.g. biotic oxygenation of soft sediments), are dynamically coupled to the system, and are not part of the extrinsic environment. Climatic factors are part of the extrinsic environment. Some large-scale characteristics of the water masses delivered by currents to a community, including volume flux, temperature, and salinity, are likewise extrinsic factors. Other aspects of these water masses, including small-scale variations in flow speed and turbulence, are influenced by the resident biota and are part of the coupled system. Anthropogenic factors, including eutrophication, trends in alteration of climate, and pollution, are part of the extrinsic environment because their rates of action are not affected by community dynamics. How local-scale human interference is construed depends on whether or not one considers humans as part of the resident biota (Petraitis \& Dudgeon 2004). To summarize, we use the term 'environment' in this paper to denote parameters that are largely unaffected by community dynamics. Ecologists typically estimate environmental conditions with averages and variances, focusing on those extrinsic parameters that exert significant effects on density or population growth rate (Connell \& Sousa 1983, Sousa \& Connell 1985).

Second, the successional trajectories (black line in Fig. 2A) a community follows in phase space are deterministic (assuming no intervening perturbations), although the starting point immediately following a disturbance may be random (i.e. stochastic, or of variable type and magnitude). Stochastic perturbations during succession are jumps to different points in the phase portrait and result in mosaics of patches of varying age. Each potential trajectory during succession is the smooth curve that results from the integration of
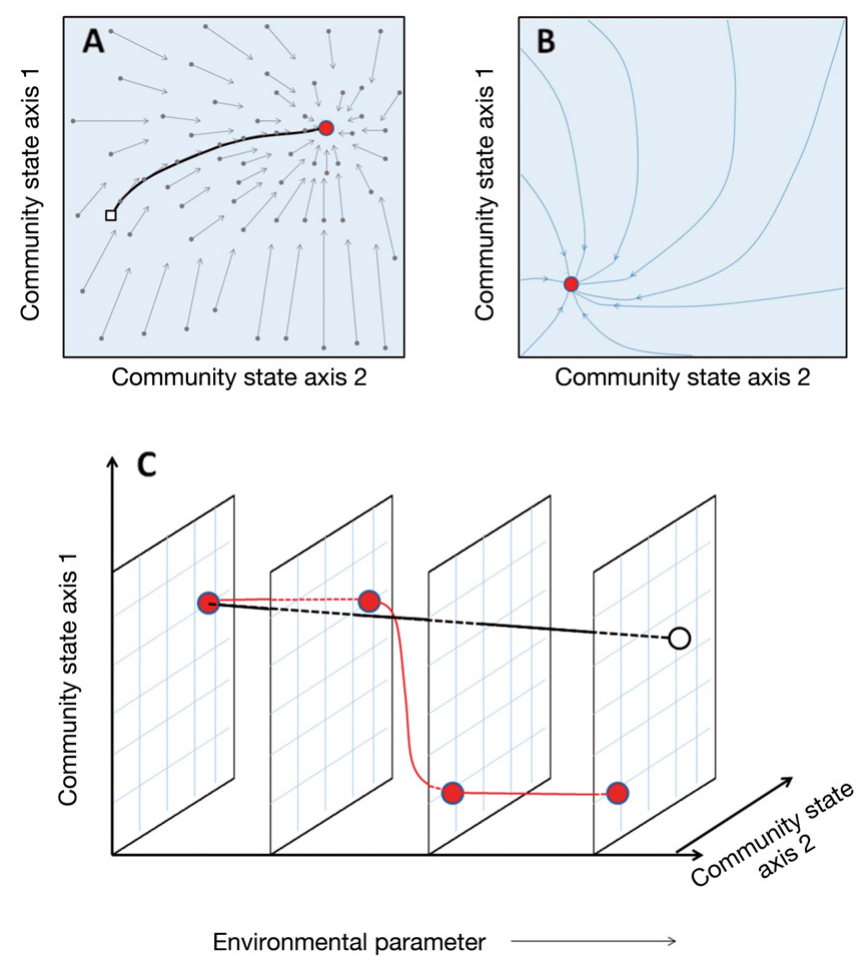

Fig. 2. Phase portrait and phase shift. (A) Phase portrait of a community showing attractor (red circle), vector field (gray arrows) in the state space (blue shading), and a possible starting point (open square) for a trajectory of succession (solid black line). (B) Phase shift of community state associated with environmentally driven changes in the vector field (i.e. interactions between species and their environment). Red circle: attractor, blue arrows: successional trajectories in the state space (blue shading). (C) The dynamic range of shifts in phase portraits of a community as a function of environmental change. Two examples of different phase-shift trajectories are shown. Solid red circles and red line: a threshold phase shift occurring between the middle 2 environments. Open circles and black line: a linear phase shift (circles: attractors for each phase portrait at a specific value of an environmental parameter along the abscissa, lines: dynamics of changes in the phase portrait as a function of environmental change). Modified from Abraham \& Shaw (1992)

tangent vectors (gray vectors associated with the black line in Fig. 2A, one vector for each point in the phase space) that drive the system toward its attractor (Abraham \& Shaw 1992). In ecologists' terms, the vector field (the collection of gray arrows in phase space) represents the instantaneous rates of change in community state at each point in phase space caused by interactions of species with their environment and with each other. The direction and magnitude of a vector represent the net effect of different types and strengths of interspecific interactions unique to that assemblage and environment. This abstraction of the vector field underlies a central theme in community ecology: At a site with a specific set of environmental conditions 
under which a single stable community can persist, interactions among species under those conditions will always lead to the same equilibrial assemblage (Lewontin 1969).

\section{Phase shifts and alternative stable states}

Phase shifts and alternative stable states are equilibrial views of community structure. Many ecologists view equilibrium as an inaccurate characterization of reef ecosystems; however, as Petraitis et al. (1989) pointed out, the debate over whether particular systems are equilibrial or non-equilibrial is largely artificial. Both views emphasize the operation of the same underlying processes, but at different spatial and temporal scales. The influence of scale and the possibility of dynamic equilibria make it very difficult to distinguish equilibrial from non-equilibrial systems and phase shifts from alternative stable states.

Phase shifts

Environmentally driven changes in the vector field imply changes in the strength or nature of species interactions. Changes in the vector field alter successional trajectories and the equilibrium of the phase portrait. A change in the phase portrait of a community associated with environmental change in space or time is a phase shift (Fig. 2B). For example, the change in abundance and composition of species associated with the transition from a sheltered bay to a rocky headland is a phase shift in space. Ecologists have tended to emphasize phase shifts in time, especially for cases in which environmental changes, perhaps accrued over time, have caused abrupt and dramatic changes in species composition. An important example is the transition from corals to macroalgae observed on some coral reefs (Hughes 1994, Petraitis \& Hoffman 2010, this Theme Section). The essential feature characterizing a phase shift is that the shift in the community assemblage is caused by a persistent change or trend in the environment, because under each specified set of environmental conditions, there is only a single attractor, or equilibrial community.

Phase portraits of different environments arrayed along an axis integrating that environmental change reveal the dynamic range of a phase shift (Fig. 2C; Petraitis \& Dudgeon 2004). The biotic changes may constitute large or small changes in a community, and there is no criterion for the extent of alteration required to call a change a phase shift (Rogers \& Miller 2006, Bruno et al. 2009). Essentially, if one specifies a priori the minimum amount of change in a community eco- logically meaningful and such a change can be detected statistically, then there is evidence of a phase shift. A large phase shift precipitated by a small change in a single environmental parameter-a threshold phenomenon-is easily detected because a slight environmental change causing dramatic changes at the community level is likely to occur in a short time. At the other end of the spectrum, a small change in a community as a function of environmental change may be barely detectable, particularly if the rate of change in the environment is slow (black line in Fig. 2C).

Concepts of resilience (Lewontin 1969 [therein called 'relative stability'], Holling 1973, Grimm \& Wissel 1997, Nyström et al. 2008) are inextricably linked with phase shifts. Lewontin (1969) conceptualized the resilience of a system using the now-traditional ridgeand-valley phase portrait, with a rolling ball representing the trajectory of the community. The ball rolls towards the stable state, represented by the lowest, least energetic point on the landscape. Resilience is positively related to the steepness and depth of the basin(s) of attraction, with steep and deep basins being more resilient than shallow ones. The notion of a community losing resilience is depicted by the shallowing and flattening of the basin of attraction in which the community resides (Nyström et al. 2000, Beisner et al. 2003). This change in the phase portrait is caused by environmental change: the movement of the system along the abscissa of Fig. $2 \mathrm{C}$ to a new phase portrait, in which changes in the vector field (e.g. shorter vectors, less determinism, different trophic structure, etc.) cause the community to move within the basin of attraction more easily. Shallow phase portraits are those near the threshold for which any further loss of resilience with environmental change will shift the equilibrium to a new location, corresponding to a different community. Thus, lowered resilience is associated with greater likelihood of phase shifts.

The term 'regime shift' has recently become popular, particularly in the literature on fisheries and pelagic ecosystems (Hare \& Mantua 2000). Regime shift is generally used synonymously with phase shift. Like phase shift, regime shift is used to describe changes in either biotic or abiotic conditions, or both (Hare \& Mantua 2000, Scheffer et al. 2001, Kaiser et al. 2005). The 2 terms mean the same thing and they are distinctly different from alternative stable states. A number of recent papers have incorrectly defined phase shifts as alternative states and regime shifts as alternative stable states (Beisner et al. 2003, Hughes et al. 2005, Nyström et al. 2008). Redefining these widely recognized ecological terms ignores precedent (Lewontin 1969, Connell \& Sousa 1983, Peterson 1984, Sousa \& Connell 1985), divorces 
coral reef science from the broader field of community ecology, and is retarding the progress of the discipline.

\section{Alternative stable states}

The distinctive feature of alternative stable states is the presence of $>1$ basin of attraction in a given phase portrait (Fig. 3A; cf. Fig. 2, in which only 1 basin occurs in any phase portrait). In ecological terms, this means that a single set of environmental conditions can support $>1$ successional end-state (Lewontin 1969, May 1977, Connell \& Sousa 1983, Peterson 1984, Sousa \&

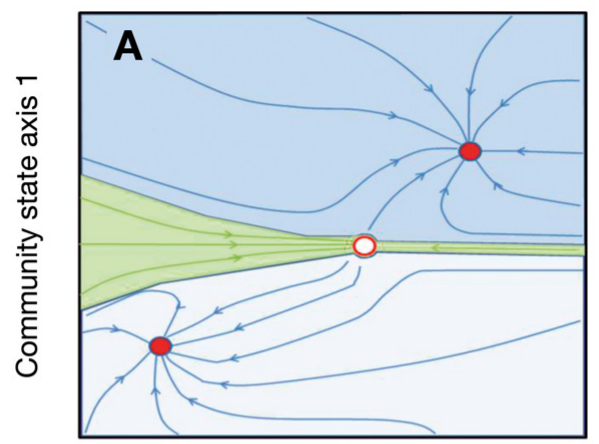

Community state axis 2

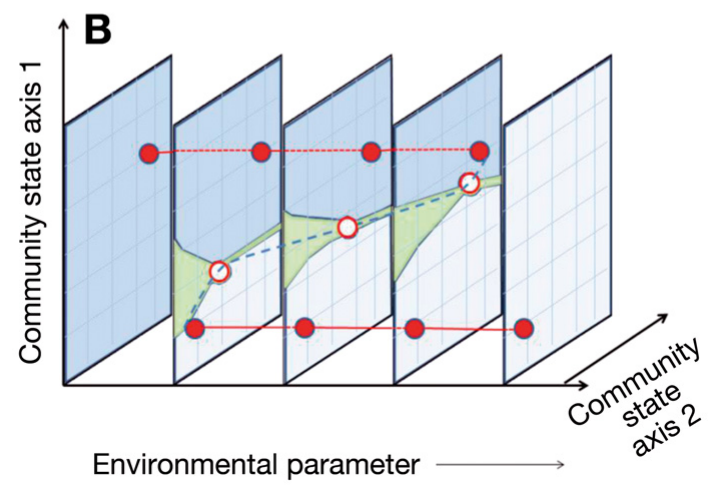

Connell 1985, Petraitis \& Dudgeon 2004, Schröder et al. 2005). In practice, any significant differences between abiotic conditions occupied by alternative states in space or time must demonstrably be caused by different resident populations rather than originating extrinsically (Sousa \& Connell 1985). Reef scientists have often ignored the requirement that multiple assemblages (or points in phase space) must be stable under a single set of environmental conditions, thereby confusing phase shifts with alternative stable states. Contrary to the view of Beisner et al. (2003), community changes that result from trends of environmental change are not alternative states; they are merely phase shifts, which essentially amount to natural demonstrations of the control of populations by abiotic and biotic factors.

The theory of alternative stable states implies that the outcome is contingent upon the starting conditions - the basin of attraction in which the starting point is located. What processes cause communities to move from one basin of attraction to another? Petraitis \& Latham (1999) described hypothetical scenarios in which a pulse of recruitment or mortality might move the system between basins of attraction in the absence of environmental variability. Lewontin (1969) and May (1977) recognized that natural environments are variable. Slight fluctuations in time that are associated with the natural range of environmental conditions, or

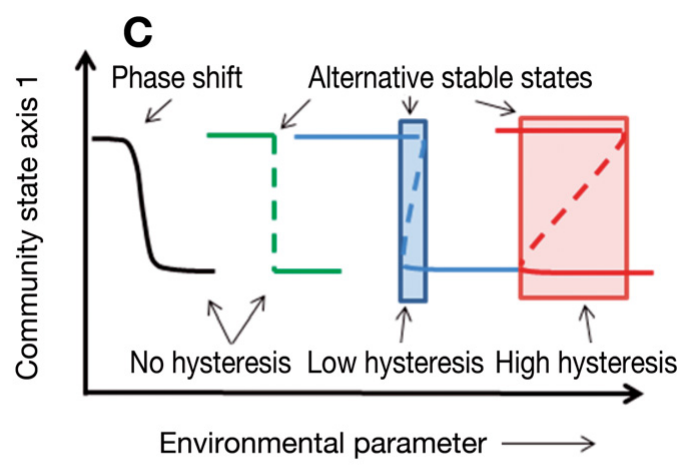

Fig. 3. Alternative stable states. (A) Phase portrait plotted in 2 dimensions showing 2 alternative stable states. There are 2 separate basins of attraction (shaded light blue/grey and blue), with dark blue arrows in each indicating successional trajectories towards their respective attractors (solid red circles). The separatrix between the alternative states (often visualized as a ridge or saddle, and here shaded green) has an unstable equilibrium point (open red circle), departures from which can lead to either alternative state. The dark green arrows within the separatrix are trajectories leading to the unstable equilibrium. The separatrix is depicted as a broad surface simply to illustrate that it need not be a line. (B) Several phase portraits plotted in 2 dimensions and arrayed along the axis of a key environmental parameter, showing single equilibrial states at low and high values of the environmental parameter, and multiple stable equilibria at intermediate values. The blue dashed line connecting unstable equilibria of different phase portraits is the breakpoint (May 1977) or threshold curve (Petraitis \& Hoffman 2010). The environments over which multiple stable equilibria exist determine hysteresis in the system. Note that basins of attraction and separatrices may display different shapes in different phase portraits. (C) Variable hysteresis in different systems, ranging from none (phase shift or multiple stable states in a single environment), to small (multiple stable states only over a small number of distinct environments, blue-shaded region), to large (multiple stable states over many distinct environments, red-shaded region). Solid lines: stable equilibria at particular values of environmental parameters. Dashed lines: breakpoint curves, which are ridges of unstable equilibria distinguishing stable states in each environment. In contrast to hysteresis shown by shaded regions, the stable equilibria outside of shaded regions represent resistance of community state to environmental change. Panels (A) and (B) modified from 
perturbations (stochastic or otherwise), can cause spectacular, discontinuous shifts in state variables, moving the system across the separatrix (the saddle) between basins of attraction, but the environment is effectively the same before and after the event (Lewontin 1969). May's (1977) conceptualization differs and can be visualized by arraying phase portraits determined for each environmental condition along an environmental axis (Fig. 3B). This is the now-familiar S-shaped curve, characterized by 2 discontinuity thresholds at given values along the environmental axis, and the separatrix (the dashed line), which is the boundary between basins of attraction.

The range of environments (or sets of parameter values) over which alternative stable states are possible determines the extent of hysteresis in the system (Fig. 3C). By hysteresis, we mean (1) the lack of change in community state following manipulation of parameters within the range of values between different critical environmental conditions that cause forward and backward switches of state; and (2) the different paths followed by communities upon crossing the thresholds for forward and backward switches (Scheffer et al. 2001). If a wide range of environments characterizing an ecosystem can support alternative states, then hysteresis is strong and even large directional shifts along the environmental axis of interest may be insufficient to tip the system to an alternative state. On the other hand, if alternative states occur only within a narrow range of environments, then hysteresis is weak and the system can be tipped back to an alternative state far more easily. Finally, and critically, if alternative states exist in only a single environmental condition, or if there are no alternative states in any environment, then there is no hysteresis in the system. In either case, a reversal of direction along the environmental axis will initiate restoration of the prior community, and forward and backward trajectories will differ only trivially. Establishing the extent of hysteresis is essential to ecosystem management; it is critical to establish the environmental range (if any) over which alternative states are possible.

\section{Demonstrating alternative stable states}

There are 2 robust approaches to demonstrating the existence of alternative states. The first is to show by experiment that a pulse perturbation (sensu Bender et al. 1984) can cause a switch between different, stable community assemblages at the same site in the absence of persistent environmental changes (Connell \& Sousa 1983, Peterson 1984). Conditions before and after pulse perturbations can be the same because by definition, the pulse is an ephemeral event between periods of the same environmental regime. Press perturbations, on the other hand, are inappropriate for demonstrating alternative stable states because by definition environmental conditions before and after the perturbation are different. Moreover, an argument for alternative stable states requires a demonstration that any positive feedbacks that stabilize the currently resident community and resist invasion by the alternative community are biotically driven and constitute the sole source of modifications of the physical environment (Peterson 1984, Sousa \& Connell 1985, Schröder et al. 2005).

The criterion for spatial scale over which alternative states occur is the minimum area required for populations of dominant species to be self-sustaining (Connell \& Sousa 1983). The criterion for temporal stability of alternative states has been more controversial. Petraitis \& Dudgeon (2004) and Petraitis et al. (2009) argued that demonstrating resilience of invading assemblages to small perturbations was preferable evidence of stability to the temporal criterion of Connell \& Sousa (1983), which is the time to self-replacement of the longest-lived component of the community. In this sense, and contrary to the views of others (e.g. Scheffer et al. 2001, Bellwood et al. 2004), community resilience is positively correlated with alternative stable states where they occur. The designs and analytical approaches required for valid experimental tests are reviewed by Petraitis \& Dudgeon (2004) and demonstrated by Petraitis et al. (2009).

The second approach is indirect and more difficult to execute. As Petraitis \& Hoffman (2010) point out, a system with multiple stable states in $>1$ environment must have at least 2 discontinuous thresholds, each at a unique value along an environmental axis, to generate the S-shaped curve of Fig. 3C. One could infer the existence of alternative stable states from experimental evidence showing a switch from one state to another at a specified value of an environmental parameter and the switch back to the first state at a different parameter value. An experiment of this sort is unlikely to be performed for ethical and logistical reasons, because the scale and magnitude of the required pulse perturbation(s) are unknown. No other type of evidence is admissible (Petraitis \& Dudgeon 2004, Petraitis et al. 2009).

Recent efforts to characterize reef communities as exhibiting alternative, stable, hard-coral and non-coral states have attempted to circumvent the difficulties of direct tests and to explain the long-term persistence and apparent stability of non-scleractinian community states relative to that of scleractinians. These studies have focused on 3 lines of evidence (Mumby 2009): empirical identification of positive feedbacks, demonstration of hysteresis, and modeling. None of these 
lines of evidence in isolation, however, indicates the existence of alternative stable states. We evaluate feedbacks and hysteresis here, and defer discussion of modeling to a later section.

Positive feedbacks are thought to be especially important in establishing one successional outcome in an environment that could support different successional outcomes, but they are not in and of themselves evidence for alternative stable states. Some reef scientists consider positive feedbacks to be signatures of alternative states, but they are ubiquitous in ecological systems (Bruno \& Bertness 2001). In the context of alternative stable states, they must also explain all differences in abiotic conditions between states (Sousa \& Connell 1985).

Likewise, evidence of hysteresis is not evidence for alternative stable states for reasons of logic, interpretation, and practicality. The logical problems are twofold. First, alternative states may occur without hysteresis (Fig. 3C, see also Petraitis \& Hoffman 2010). Second, tests of hysteresis are tautological because they implicitly assume that multiple stable states occur across a range of environments prior to demonstrating their existence in any single environment.

Tests of hysteresis may also suffer from problems of biased interpretation. There is a misconception that phase shifts are easily reversible (see Mumby 2009), whereas alternative states are not. This is not necessarily true. Phase shifts may be far more difficult to reverse than alternative states if they are the products of large and persistent environmental changes that are not easily reversed, such as a spill of toxic chemicals. Moreover, if the environment has changed in several parameters, which may be independent or negatively correlated, then reversal of a phase shift through attempted environmental restoration is unlikely. Failure to appreciate these possibilities may lead to the interpretation of community stasis as only being the result of hysteresis.

Finally, there are practical difficulties that further complicate the interpretation of hysteresis in experimental outcomes. The magnitudes of environmental pulses that are necessary to cross ecological thresholds are usually unknown. Manipulation of environmental parameters may be of insufficient magnitude to cause a switch. In such cases, experimental tests of hysteresis rely on negative evidence-no community response to environmental manipulation - for which the probability of a Type II error is, therefore, also unknown. Moreover, misconstruing the identity of the parameter putatively causing a switch between states will yield no community change following manipulation. Inferring alternative states from such a result will obviously be faulty because the hysteresis will be illusory.

\section{PHASE SHIFTS AND ALTERNATIVE STABLE STATES ON CORAL REEFS}

Petraitis \& Dudgeon (2004) reviewed evidence of changes in community state in tropical reef ecosystems around the world in the context of whether those changes represented either phase shifts or alternative stable states. Three key points from that review are relevant here. First and most important, the authors found no evidence in support of the hypothesis that coral and macroalgal assemblages represent alternative stable states of reef communities from studies published through 2003. Second, these studies, and studies published after 2003, frequently blurred the distinction between phase shifts and alternative stable states and erroneously concluded that coral reef systems represented alternative stable states (e.g. Nyström et al. 2000, 2008, Scheffer et al. 2001, Elmhirst et al. 2009, Norström et al. 2009, Riegl et al. 2009). Third, cases of persistent shifts from coral to macroalgal assemblages tended to be isolated in specific areas (Ninio et al. 2000), whereas other areas showed no such shifts over ecological time scales that were relatively long (Connell et al. 1997, Bruno et al. 2009).

Intensified study of coral reefs, which is largely driven by concern about the effects of climate change, warrants a fresh assessment of whether the observed changes represent phase shifts or alternative stable states. Below we evaluate several cases from the recent and older literature that have been proffered as demonstrations of alternative stable states. With one exception, the evidence corroborates the conclusions of Petraitis \& Dudgeon (2004).

\section{Chronic perturbations, time and alternative states}

The first reference to alternative community states on coral reefs of which we are aware is from Lighty (1980). He inferred that stress conditions introduced by off-bank transport of turbid and episodically cooled waters in the late Holocene led to the demise of the Acropora-dominated Abaco reef system in the Bahamas. In this scenario, mortality of the cold-sensitive acroporids - the elkhorn coral Acropora palmata and the staghorn coral A. cervicornis-around $3000 \mathrm{yr}$ ago was followed by conversion to an alternative community state dominated by macroalgae and octocorals, which persists to this day (Lighty 1980, A. C. Neumann pers. comm.). The failure of the acroporids to recover can be directly attributed to the northerly location of the Abaco reef system and its continual exposure to cold-water stress. Do the coral- and macroalgae-dominated phases actually constitute alternative stable states? The only valid test would be to remove the 
chronic perturbation and observe whether or not the community would respond by returning to coral dominance.

The last few decades may have provided a natural test of the hypothesis of alternative stable states. The cold-sensitive Acropora spp. have recently expanded northward in the western Atlantic region in association with decadal-scale increases in annual sea surface temperature. Acroporid corals have appeared where they had not lived for the past few thousand years (Precht \& Aronson 2004). This includes the return of A. palmata to the Abaco reef tract (Precht \& Aronson 2006a). The millennial-scale responses of the Abaco reefs to changing environmental conditions are clearly phase shifts, and there is no evidence for alternative stable states.

In a similar vein, both species of Acropora have moved up and down the east coast of Florida, apparently in response to millennial-scale warming and cooling trends, respectively (Precht \& Aronson 2004). During the early to middle Holocene (9 to $5 \mathrm{kyr}$ ago), warmer oceanic conditions off the eastern Florida Peninsula favored the accretion of an Acropora-dominated barrier-reef tract up to $10 \mathrm{~m}$ thick, ranging as far north as Palm Beach County (Lighty et al. 1978). As temperatures cooled after the mid-Holocene, the northern limit of reef growth regressed southward to the present-day limit of the Florida Reef Tract, south of Miami. As temperatures have increased again in recent years, acroporids have re-expanded northward. Reef-coral assemblages dominated by living thickets of A. cervicornis were discovered off Fort Lauderdale in 1998 (reviewed by Precht \& Aronson 2004). Although the temporal scale of the phase shifts has been large, it appears that when the abiotic conditions have been suitable, acroporid reefs have dominated. When conditions have deteriorated, other taxa such as octocorals, sponges, and macroalgae have persisted. Millennial-scale persistence in this case should not be confused with the existence of alternative stable states.

\section{Houtman Abrolhos Islands, Western Australia}

Hatcher (1992) argued that environmental conditions were broadly similar along the Houtman Abrolhos archipelago off Western Australia. Reef areas were dominated by either macroalgae (kelps) or hard corals, which Hatcher (1992) interpreted as representing alternative stable states. Smale et al. (2010), however, showed that kelps, hard corals, and other benthic epifauna in the Houtman Abrolhos changed predictably along a latitudinal gradient. Furthermore, kelpand coral-dominated communities expanded and contracted their geographic ranges in response to histori- cal climate change (Greenstein \& Pandolfi 2008). As in eastern Florida and the northern Bahamas, environmental tracking on long temporal scales is very different from the stability of community types.

\section{Kaneohe Bay, Hawaii}

Kaneohe Bay is a classic example of cases where environmental changes have caused phase shifts. Wastewater input resulted in nutrient enrichment, causing a transition from coral to macroalgal dominance (Banner 1974). After $>2$ decades of discharge, 2 sewage outfalls were diverted from the bay in 1977-1978. The diversions were followed by rapid and dramatic declines in nutrient levels. There was a correspondingly rapid return to coral dominance (Maragos et al. 1985). If the reef ecosystem in Kaneohe Bay existed in alternative stable states, the reduction of nutrients through improvements in water quality should not have resulted in a rapid shift back to the coral-dominated configuration, regardless of ensuing complications (Hunter \& Evans 1995, Stimson \& Conklin 2008).

\section{Uva Island, Panama}

The 1982-1983 El Niño event dramatically affected community composition and net production of calcium carbonate on the reef at Uva Island, off the Pacific coast of Panama (Eakin 1996). Following mass mortality of the dominant branching corals Pocillopora spp., population densities of the herbivorous echinoid Diadema mexicanum increased dramatically and remained high until the 1990s. The abundant $D$. mexicanum rapidly bioeroded the reef framework, and their grazing on coral spat resulted in recruitment failure. Bellwood et al. (2004) cited this situation as an example of an alternative stable state representing one endresult of reef degradation: the bioeroded urchin barren. Eakin (2001) had already noted, however, that although coral cover remained low $(<10 \%)$ through the period of elevated sea urchin density, Pocillopora slowly recovered in the mid- and late 1990s as sea urchin densities declined. Reef dynamics at Uva Island represented a phase shift and were not consistent with the hypothesis of alternative stable states.

More recently, Fong et al. (2006) reported a transition from coral to macroalgal dominance at Uva and nearby Cavada Island following the 1997-1998 El Niño-Southern Oscillation (ENSO). Macroalgae persisted for several years afterwards despite the presence of consumers by virtue of their association with an unpalatable cyanobacterial epiphyte. The results of 
short-term press experiments manipulating nutrients and grazing were intriguing but still inadequate to infer alternative states (Fong et al. 2006). The extent of changes in the post-ENSO abiotic environment was also unclear.

\section{Discovery Bay, Jamaica}

The dynamics in reefs along the north coast of Jamaica, and especially the reef at Discovery Bay, have been generalized as a model of reef decline for the Caribbean region over the past few decades. Some of these generalizations have been correct but other conclusions from Jamaica have been applied inaccurately to the rest of the Caribbean (Precht \& Aronson 2006b, Bruno et al. 2009). After repeated disturbances, including Hurricane Allen in 1980; outbreaks of corallivores and coral disease in the early 1980s; Hurricane Gilbert in 1988; a number of coral bleaching events in the late 1980s; and the regional, disease-induced mass mortality of the herbivorous sea urchin Diadema antillarum in 1983-1984 (Lessios 1988), coral cover on Jamaican reefs fell from $>40$ to $<10 \%$ (Liddell \& Ohlhorst 1992, Hughes 1994). Macroalgae became the dominant benthic functional group, exceeding $60 \%$ absolute cover in many places. Although these disturbances and their immediate effects were well documented, several reef scientists have asserted that the decline of reefs in Jamaica was ultimately caused by overfishing (Knowlton 1992, Hughes 1994, Nyström et al. 2000, Jackson et al. 2001), which, they have suggested, laid the foundation for ecosystem collapse. In the overfishing scenario, large predators were depleted centuries ago, and fishers subsequently overexploited herbivorous fishes. Finally, the mass mortality of $D$. antillarum, the grazing activity of which had masked the loss of herbivorous fishes (Jackson et al. 2001), triggered a proliferation of macroalgae that flipped the reefs into an alternative stable state (Knowlton 1992, Palumbi et al. 2008, and many others). Edwards \& Gomez (2007, p. 7) stated:

In 1983, there was a mass die-off of the Diadema urchins from disease, with densities being reduced by $99 \%$. At this point, the last bastion of herbivorous control was breached and firstly shallow reefs and then deeper reefs were taken over by macroalgae. By the late 1980s, the reefs had largely shifted to an alternative stable state with $70-90 \%$ algal cover. From a restoration point of view, this alternative state is probably an order of magnitude harder to restore than the various degraded versions of the coral dominated system that persisted before the Diadema die-off. To regain the original state, not only is there a need for management measures (passive restoration) to shift conditions [back to high coral cover], but there is likely to be a need for some large active restoration disturbance (fisheries management and/or urchin culture to restore herbivory) to remove macroalgae and add corals before the system is likely to have any chance of flipping back.

The scenario is plausible, but is it accurate for Jamaica, let alone the wider Caribbean?

Populations of Diadema antillarum along much of the north coast of Jamaica have recovered patchily since the late 1990s, resulting in significant top-down changes to the benthic community in these areas of recovery (Woodley 1999, Aronson \& Precht 2000, Edmunds \& Carpenter 2001, Cho \& Woodley 2002, Bechtel et al. 2006, Idjadi et al. 2010). Carpenter \& Edmunds (2006) reported similar observations from reefs elsewhere in the Caribbean.

At Dairy Bull reef near Discovery Bay, the benthic community had completely returned to the coraldominated state by 2005 (Fig. 4), with a species composition closely resembling the pre-1980 community (Idjadi et al. 2006), following recovery of the local Diadema antillarum population to half of their premortality density (Edmunds \& Carpenter 2001). Coral populations collapsed again to even lower abundance than before the reversal, following the bleaching event of 2005 (Quinn \& Kojis 2008). The community has since returned once again to the coral-dominated state (Fig. 4; Crabbe 2009). There were no detectable changes in fish populations or improvements in water quality between 1980 and the late 1990s (Cho \& Woodley 2002, Webber et al. 2005, Greenaway \& GordonSmith 2006, Hardt 2008). The reversion to coral dominance at Dairy Bull and other reefs appears to be predicated almost exclusively on the recovery of $D$. antillarum, which can singlehandedly drive reductions in macroalgae and recovery of coral populations to their initial abundance and species composition.

Connell \& Sousa (1983) proposed that alternative stable states should be recognized based on the generation times of the affected organisms. The apparent rapidity of the recent coral-to-macroalgae transition contrasts with the much longer time that presumably will now be required for coral recovery at many other sites. It is tempting to infer that time to transition is directly related to resistance to transition and, therefore, to conclude that the system exhibits hysteresis (McManus \& Polsenberg 2004, Norström et al. 2009); however, asymmetries in the observed times required for transitions between states do not necessarily indicate hysteresis. Jackson and colleagues (Jackson \& Johnson 2000, Jackson et al. 2001, Pandolfi et al. 2003) have argued that there was a delay of at least several centuries between the time humans began interfering with coral reefs and the time those reef communities finally collapsed in the 1980s. If this surmise is correct, and if time is a valid proxy for resistance to transition, then the multicentennial transition from coral to 


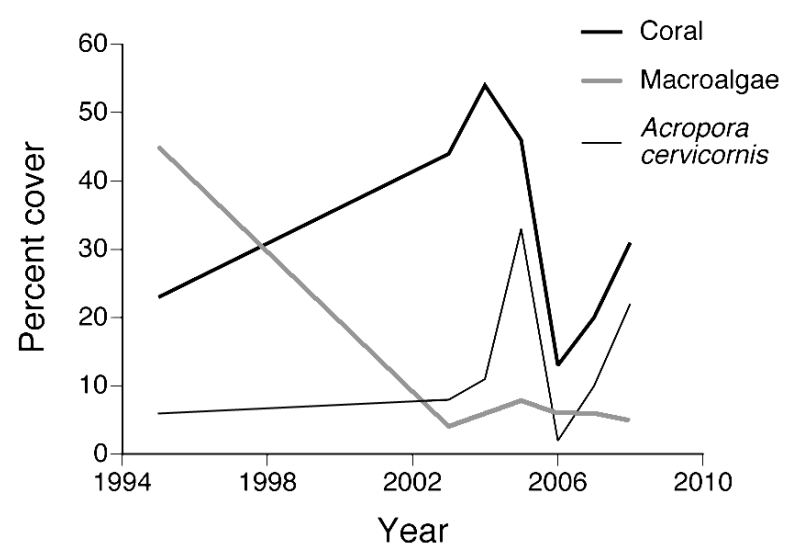

Fig. 4. Temporal trends in the total cover of hard corals, macroalgae, and Acropora cervicornis at Dairy Bull, a reef site on the north coast of Jamaica. Data from Idjadi et al. (2006) and Crabbe (2009)

macroalgal dominance was much more difficult than the decadal-scale recovery of corals that was noted, for example, at Dairy Bull. Of course, time to recovery is not related to difficulty of transition, so the time course of a transition has no bearing on hysteresis or alternative community states. The biotic stability of coral reefs on centennial, millennial, and longer time scales is most parsimoniously viewed as an indication of the stability of environmental drivers (Aronson et al. 2002a, $2002 b, 2005)$, in the absence of evidence to the contrary (Ivany et al. 2009).

Coral and macroalgal dominance cannot be alternative stable states, as Mumby and colleagues claimed they are, if restoring grazing pressure reverses the recent shift from coral to macroalgal dominance, as they also suggested (Mumby 2006, Mumby et al. 2007a, Mumby \& Harborne 2010). Instantaneous observations have shown that reefs exist along continua of coral and macroalgal cover (Bruno et al. 2009), supporting the phase-shift interpretation. In response, Mumby (2009) advanced the intriguing suggestion that alternative stable states could be apparent on ecological scales but latent on microecological scales. This idea may have merit, but Bruno et al. (2009) cannot be construed as corroborating the alternative-states hypothesis when their data support the phase-shift interpretation.

In summary, hurricanes and other disturbances killed the corals along the north coast of Jamaica. The decimation of Diadema antillarum facilitated an increase in macroalgae because there were few other herbivores present, although observations on other Caribbean reefs have shown that mass coral mortality alone is sufficient to precipitate the transition from coral to macroalgal dominance (Aronson \& Precht 2006). Finally, the return of $D$. antillarum a mere 1.5 decades later restored the coral-dominated state. This appears to have been a simple phase shift, in which the macroalgal state was not a stable alternative (Knowlton 2006), and no evidence of ecologically significant hysteresis was noted. The increase in macroalgae and the loss of coral cover were easily reversed when only one of several disturbances - the exogenously caused loss of $D$. antillarum-was alleviated.

\section{Other examples of community shifts on coral reefs}

Reef scientists have been documenting temporary, post-disturbance shifts to macroalgal dominance for half a century. A large literature from the 1960s and 1970s describes the effects of coral-killing disturbances, including storms and predator outbreaks, on reef community structure in both the Caribbean and the Indo-Pacific (Chesher 1969, Endean \& Stablum 1973, Stoddart 1974, Connell \& Slatyer 1977, Connell 1997, Diaz-Pulido et al. 2009). Belizean reefs responded to extensive damage from Hurricane Hattie in 1961 with a shift from corals to macroalgae, >2 decades before the Diadema antillarum mass mortality. Macroalgae dominated for $>1$ decade before corals recovered on these unfished reefs (Stoddart 1963, 1969, 1974). Whether macroalgal dominance represented a phase shift or more simply a successional stage remains unresolved.

More recently, high sea surface temperatures in December 2005 to January 2006 triggered mass coral bleaching and mortality on Acropora-dominated reefs of the Keppel Islands in the southern Great Barrier Reef (Diaz-Pulido et al. 2009). The reefs rapidly shifted to macroalgal dominance. Corals then recovered rapidly through asexual re-expansion of the remaining fragments, outcompeting the macroalgae in $<1 \mathrm{yr}$. As in the case of Hurricane Hattie, succession appears to be the most parsimonious hypothesis.

The fished reefs of Moorea, French Polynesia have been subjected on a decadal scale to recurrent disturbances, including cyclones, outbreaks of the crown-ofthorns starfish Acanthaster planci, and temperatureinduced coral bleaching. Long-term monitoring and experimentation have documented rapid excursions from, and returns to, coral dominance (Done et al. 1991, Adjeroud et al. 2005, 2009, Berumen \& Pratchett 2006). The volatility of benthic assemblages at Moorea in response to frequent disturbance again supports an inference of succession. The hypothesis of alternative stable states is not supported, and the same can be said for reefs in the shelf lagoon of the Belizean barrier reef (Aronson et al. 2002a, 2002b) and the Great Barrier Reef (Emslie et al. 2008).

A common argument in the recent literature is that macroalgae-dominated reefs are a relatively new phe- 
nomenon, that they are becoming more frequent, and that they are a sign of anthropogenic degradation of reef ecosystems. In contrast, a recent meta-analysis of the frequency and magnitude of coral-to-macroalgae phase shifts showed that they are much less common and less geographically extensive than generally assumed: only 1 to $2 \%$ of the world's reefs surveyed between 1996 and 2006 were dominated by macroalgae (Bruno et al. 2009). This study also indicated that there has been no measurable trend toward macroalgal dominance on coral reefs since 1995. Likewise, a recently published meta-analysis of trends in coral and macroalgal cover on Caribbean reefs $(n=1962)$ found that regional and subregional mean values of macroalgal cover have not changed since the mid-1980s (Schutte et al. 2010). The regional mean macroalgal cover from 2001 to 2005 was $15.3 \%$, which hardly suggests a Caribbean-wide phase shift to macroalgal dominance.

It bears repeating that transitions from coral dominance do not necessarily lead to macroalgaedominated systems. Results of phase shifts include reef communities that are dominated by sea anemones (Chen \& Dai 2004), corallimorpharians (Loya 2004), sponges (Aronson et al. 2002b), and octocorals (Davis 1982).

\section{Ship groundings}

Ship groundings have long been put forth as potential examples of alternative stable states resulting directly from human disturbance to coral reefs. Four years after a ship grounding on the Great Barrier Reef, Hatcher (1984) noted that persistent macroalgal dominance in the absence of a measurable wreck-derived influence provided circumstantial evidence that it represented an alternative stable state. The metal hull of the grounded vessel remained, however, and it now seems likely that iron leaching from the vessel's corroding hull stimulated and maintained the macroalgal bloom; similar phase-shift responses have been reported from other ship-grounding sites at which corroding metal debris remained (Schroeder et al. 2008, Work et al. 2008). These examples suggest that removing ships grounded on coral reefs should reduce the potential of a phase shift to dominance by macroalgae and other undesirable taxa.

How do reefs respond to ship groundings from which the ship has been removed? If a ship grounding flattens the topography of a highly structured reef habitat, and if topographic complexity does not recover through coral growth, the community can develop so as to converge on that found in natural hardground habitats. Hardground communities typically consist of flat limestone pavements dominated by turf and crus- tose coralline algae, gorgonians, and isolated coral colonies. This is precisely what happened at the 'Wellwood' ship-grounding site in the Florida Keys (Aronson \& Swanson 1997a, Precht et al. 2001). In 1984, the $122 \mathrm{~m}$ freighter MV 'Wellwood' struck and flattened a $1500 \mathrm{~m}^{2}$ section of the shallow spur-and-groove zone at Molasses Reef, which at the time was dominated by topographically complex stands of Acropora palmata. Aronson \& Swanson (1997a,b) surveyed the 'Wellwood' site in 1995 to 1996 at 4 to $7 \mathrm{~m}$ depth and found it to be quantitatively more similar to reference sites that were hardgrounds than to undamaged, reference sections of spur-and-groove habitat adjacent to the grounding. Abiotic conditions were essentially the same before and after the damage.

One of the hardground reference sites, Pickles Reef, which in 1995 was thought to represent a natural hardground, turned out to be the site of 2 earlier ship groundings: 1 in $\sim 1800$ and the other in 1894. Scattered debris from the two 19th-century groundings was still visible, but the Pickles Reef reference site was otherwise indistinguishable from a second, truly natural hardground site used as reference. The hardground at Pickles Reef was bounded laterally by spurand-groove habitat, which was dominated by Acropora palmata. Pickles Reef provides strong circumstantial evidence that ship groundings can produce long-lived hardgrounds, and it is plausible that these hardgrounds resist conversion back to spur-andgroove habitats on a decadal to centennial time scale. Spur-and-groove and hardground communities of the Florida Keys are candidates for alternative stable states, although once again resistance has not been demonstrated. Alternative states or not, restoring shipgrounding sites clearly must include reestablishing topographic complexity (Precht et al. 2001).

\section{THEORETICAL CONSIDERATIONS}

For the most part, studies of the recent shift from corals to macroalgae have been non-experimental, unreplicated, and uncontrolled. Executing well-designed experiments would be a challenge and would require at least several years before strong inferences could be drawn. Such difficulties have motivated modeling studies of community dynamics. A recent quantitative model characterized Caribbean reefs as switching between alternative, stable, coral and macroalgal states with changes in the intensity of herbivory (Mumby et al. 2007a, Mumby 2009); however, there are 2 fundamental problems with this and related models (Elmhirst et al. 2009). These problems call into question the utility of the models for resolving the issue of phase shifts and alternative states. 
First, the axes of environmental parameters (e.g. those displayed along the abscissa of Fig. 3B) represent only extrinsic environmental features. Biotic interactions, such as grazing rate, are components of the vector field in any given phase portrait, i.e. under any specific set of physico-chemical conditions grazing rate is dynamically coupled to the system (Schröder et al. 2005). The use of grazing intensity as the environmental parameter upon which to delineate multiple stable points is, therefore, inappropriate; rather, the variation in grazing intensity is described by variation in vectors within phase portraits. Indeed, using any parameter that is dependent on another state variable of the system merely shifts the question to a different level: Does the consumer in question ever naturally exist at multiple stable equilibria in one environment? Both Paine (1977) and Connell \& Sousa (1983) recognized this problem and persuasively argued that communities with high and low abundances of consumers (or high and low predation intensities) cannot be regarded as stable alternatives, because when consumers increase in abundance they regulate prey abundance, leading the system (in this case) to a coral-dominated community. The results of Mumby's model show the expected pattern of return to coral dominance as grazing intensity increases. The question is whether variation in grazing intensity (or, as a proxy, grazer abundance) in the model is itself stable at any value (Knowlton 1992, Palumbi et al. 2008), or whether it simply reflects the natural variability that is expected during the protracted increase in the density of Diadema antillarum from 1983 to the present.

The second problem is that the empirical values used to parameterize Mumby's model are based on independent data sets from Jamaica that spanned the 1970 s to the 1990s. In other words, the parameters reflect rates of processes in very different abiotic environments that might favor either corals or macroalgae but do not represent combinations of parameter values that could actually occur in any single natural environment. This homogenization of parameters is tantamount to ignoring the same-environment criterion for testing alternative stable states and distinguishing them from phase shifts.

\section{IMPLICATIONS FOR MANAGEMENT}

The ecological imprint of catastrophic disturbances can persist for a very long time without necessarily moving the affected community into an alternative stable state. Despite the recognition of shifting baselines in the recent literature on coral reefs, it is peculiar that reefs in Jamaica and elsewhere in the Caribbean were characterized as being locked into an alternative sta- ble state within a decade after the confluence of a number of catastrophic perturbations (e.g. Knowlton 1992). Had the expectations for recovery from these combined disturbances initially been more realistically scaled in decades to centuries, it is doubtful that coral reef ecologists would still be developing models to explore how to overcome putative hysteresis (see also Emslie et al. 2008).

Herbivore addition and exclusion experiments performed by Sammarco (1982a, 1982b) on patch reefs in Discovery Bay in the 1970s suggested that declining herbivory relative to the space available for colonization promoted algal growth and decreased coral recruitment. As Diadema antillarum decreased, macroalgal biomass increased. Once the urchins were restored, the system returned to its original composition. The response of the benthos to urchin abundance was similar in small-scale plots and whole-reef manipulations. Although no one could have predicted the compounded, catastrophic disturbances that rocked the reefs along the north coast of Jamaica in the decade following Sammarco's work, his manipulative studies should have allowed reef scientists to predict the responses of the benthos to changes in herbivory in space and time. Given that these catastrophic disturbances occurred, the increase in macroalgae that followed the loss of Diadema and the subsequent reduction of macroalgae following the recovery of Diadema highlight the predictive value of scaling up small-scale ecological experiments. For unknown reasons, this most appropriate guide to predicting the future of Jamaican reefs was overlooked by most reef scientists.

The reaction of ecologists and managers to the 1988 forest fires that burned in Yellowstone National Park serves as an excellent terrestrial counterpoint to the example of Caribbean reefs. The fires occurred during an extreme year and were the largest observed since the park was established in 1872. The last comparable fires had occurred at 1700 (Romme 1982, Romme \& Despain 1989). Had the expectation for recovery from the 1988 conflagration been scaled in years to decades, there would have been a public outcry for active intervention and restoration. A demographic analysis of trees in the adjacent unimpaired forests was combined with the life-history strategies of the affected species to develop an accurate recovery model (Romme \& Turner 2004). The model predicted that it would take at least 80 to 100 yr for the forest canopy to close and for the forests to resemble their pre-burn configuration and architecture. Despite a number of ecological surprises during the last 2 decades (Turner et al. 2003), the forests of Yellowstone are on track to recover within the century (Romme \& Turner 2004).

'The straw that broke the camel's back' is an ancient metaphor of threshold behavior that has been used in 
recent years to describe the supposed hysteresis and existence of alternative stable states on coral reefs. In the case of Jamaica, the alleged last straw after centuries of overfishing was the catastrophic loss of Diadema in 1983-1984 (Knowlton 2001). When that last straw was removed by the return of Diadema in the late 1990s, however, the camel stood up: the benthic assemblage came bounding back on its own.

The management implications of this recovery are twofold. First, the idea that without active restoration the reef will remain locked in a macroalgal state is incorrect. Why is this important? Improving fishery resources through the implementation of gear changes and establishment of marine protected areas in coastal Jamaica is a worthy management goal (Woodley \& Sary 2000, Watson \& Munro 2004). However, even at very small scales, it is a costly proposition with a poor chance of changing the trajectory of the benthic community at the landscape scale or in an ecologically relevant time frame. Second, even without their full complement of taxa and functional groups, coral reefs are not locked in alternative stable states. They can recover by alleviating the responsible stressor(s) or restoring the perturbed aspect(s) of the system (Precht \& Aronson 2006b, Idjadi et al. 2010).

In an attempt to communicate the urgency of the coral reef crisis, some authors have overemphasized the danger of irreversible thresholds (Bellwood et al. 2004). If it is all over, then apart from ethical considerations (to which we wholeheartedly subscribe), what is the 'ecological' value of protecting parrotfish and other herbivorous fishes? If on the other hand, protecting herbivores will have a salutary effect (Mumby et al. $2007 b$, Mumby \& Harborne 2010), then the damage is not irreversible as has been claimed. Single-taxon management, when used in conjunction with other management measures, can be a powerful and relatively inexpensive approach to achieving certain goals of reef conservation (Power et al. 1996, Simberloff 1998, Hilborn 2004, Aronson \& Precht 2006). For instance, no-take restrictions on parrotfish populations could limit macroalgal growth and promote coral recovery on some reefs. Protection of parrotfish, combined with a network of Sanctuary Preservation Areas (SPAs), in the Florida Keys National Marine Sanctuary could be one reason for the low algal cover on Florida's reefs (Bruno et al. 2009). Throughout the Caribbean, however, it appears that Diadema are far more effective than fish at reducing macroalgae and enhancing coral recruitment (Sammarco 1980, 1982b, Carpenter 1986, Hawkins \& Roberts 2004, Carpenter \& Edmunds 2006, Idjadi et al. 2010), so they could serve as a focal point for local conservation and management efforts, especially on reefs that are severely overfished (e.g. Macia et al. 2007). Finally, where reefs have lost their major framebuilding corals and structural complexity, restoration of foundation species is particularly important because they can facilitate the colonization of other species by maintaining or providing critical microhabitat (Halpern et al. 2007, Precht et al. 2010).

\section{CONCLUSIONS}

For coral reef scientists, the concept of alternative stable states simplifies a highly complex system of interactions, feedbacks, and measurable characteristics, yielding a dichotomy based on 1 or 2 key parameters. One class of the dichotomy (the coral-dominated community) is valued whereas the other (macroalgaedominated or coral-impoverished community) is considered degraded and undesirable, with innuendos of humanity's moral turpitude. Reef scientists have abstracted a minimalist picture of reefs flipping between the 2 extremes and then drawn on it a baroque overlay of mechanisms that lock those reefs into one state or the other. The science has been unduly influenced by the narrative that emerged from Discovery Bay, but the scenario is not even accurate for that beststudied of reefs.

The distinction between phase shifts and alternative stable states is no semantic quibble. It is a critical issue in ecology that must be resolved if we are to diagnose the situation correctly and manage coral reefs effectively. The questions that remain are: (1) whether we can restore reef environments in the face of climate change; and (2) whether we will choose to invest in the required restoration.

Acknowledgements. We thank many colleagues whose ideas and feedback have greatly influenced our thinking about disturbance dynamics in marine communities. We especially thank P. Dayton, L. Kaufman, C. 'Pete' Peterson, P. Petraitis, W. Sousa, the late J. Sutherland, L. Toth, R. van Woesik and J. Witman for advice and discussion over the years. S.R.D. was supported by the National Institutes of Health GMS-MBRSSCORE program (NIH-SO6GM48680) during the writing of this manuscript. R.B.A. and W.F.P. were partially supported by the Smithsonian Institution's Marine Science Network, and the Johnson and Hunterdon Oceanographic Research Endowments at the Smithsonian. This is contribution no. 159 from the CSUN Marine Biology Group, contribution no. 888 from the Smithsonian's Caribbean Coral Reef Ecosystems (CCRE) Program, and contribution no. 48 from the Institute for Research on Global Climate Change at the Florida Institute of Technology. The content of this manuscript does not reflect any position of the US Government or of NOAA unless otherwise specified.

\section{LITERATURE CITED}

Abraham R, Shaw CD (1992) Dynamics: the geometry of behavior. Addison-Wesley, Reading, MA 
Adjeroud M, Chancerelle Y, Schrimm M, Perez T, Lecchini D, Galzin R, Salvat B (2005) Detecting the effects of natural disturbances on coral assemblages in French Polynesia: a decade survey at multiple scales. Aquat Living Resour 18: 111-123

Adjeroud M, Michonneau F, Edmunds PJ, Chancerelle Y and others (2009) Recurrent disturbances, recovery trajectories, and resilience of coral assemblages on a South Central Pacific reef. Coral Reefs 28:775-780

Aronson RB, Precht WF (2000) Herbivory and algal dynamics on the coral reef at Discovery Bay, Jamaica. Limnol Oceanogr 45:251-255

Aronson RB, Precht WF (2006) Conservation, precaution, and Caribbean reefs. Coral Reefs 25:441-450

Aronson RB, Swanson DW (1997a) Disturbance and recovery from ship groundings in the Florida Keys National Marine Sanctuary. Dauphin Island Sea Lab Tech Rep 97-002, Dauphin Island, AL

Aronson RB, Swanson DW (1997b) Video surveys of coral reefs: uni- and multivariate applications. Proc 8th Int Coral Reef Symp, Panama 2:1441-1446

> Aronson RB, Macintyre IG, Precht WF, Murdoch TJT, Wapnick CM (2002a) The expanding scale of species turnover events on coral reefs in Belize. Ecol Monogr 72:233-249

Aronson RB, Precht WF, Toscano MA, Koltes KH (2002b) The 1998 bleaching event and its aftermath on a coral reef in Belize. Mar Biol 141:435-447

Aronson RB, Macintyre IG, Lewis SA, Hilbun NL (2005) Emergent zonation and geographic convergence of coral reefs. Ecology 86:2586-2600

Banner AH (1974) Kaneohe Bay, Hawaii: urban pollution and a coral reef ecosystem. Proc 2nd Int Coral Reef Symp, Brisbane 2:685-702

Bechtel JD, Gayle P, Kaufman L (2006) The return of Diadema antillarum to Discovery Bay: patterns of distribution and abundance. Proc 10th Int Coral Reef Symp, Okinawa 1: 367-375

Beisner BE, Haydon DT, Cuddington K (2003) Alternative stable states in ecology. Front Ecol Environ 1:376-382

Bellwood DR, Hughes TP, Folke C, Nyström M (2004) Confronting the coral reef crisis. Nature 429:827-833

Bender EA, Case TJ, Gilpin ME (1984) Perturbation experiments in community ecology - theory and practice. Ecology $65: 1-13$

Berumen ML, Pratchett MS (2006) Recovery without resilience: persistent disturbance and long-term shifts in the structure of fish and coral communities at Tiahura Reef, Moorea. Coral Reefs 25:647-653

Bruno JF, Bertness MD (2001) Habitat modification and facilitation in benthic marine communities. In: Bertness, MD, Gaines, SD, Hay, ME (eds) Marine community ecology. Sinauer Associates, Sunderland, MA, p 201-220

Bruno JF, Sweatman H, Precht WF, Selig ER, Schutte VGW (2009) Assessing evidence of phase shifts from coral to macroalgal dominance on coral reefs. Ecology 90: 1478-1484

Carpenter RC (1986) Partitioning herbivory and its effects on coral reef algal communities. Ecol Monogr 56:345-363

Carpenter RC, Edmunds PJ (2006) Local and regional scale recovery of Diadema promotes recruitment of scleractinian corals. Ecol Lett 9:268-277

Chen CA, Dai CF (2004) Local phase shift from Acroporadominant to Condylactis-dominant community in the Tiao-Shi Reef, Kenting National Park, southern Taiwan. Coral Reefs 23:508

Chesher RH (1969) Destruction of Pacific corals by the sea star Acanthaster planci. Science 165:280-283

Cho LL, Woodley JD (2002) Recovery of reefs at Discovery
Bay, Jamaica and the role of Diadema antillarum. Proc 9th Int Coral Reef Symp, Bali 1:331-338

Connell JH (1997) Disturbance and recovery of coral assemblages. Coral Reefs 16:S101-S113

Connell JH, Slatyer RO (1977) Mechanisms of succession in natural communities and their role in community stability and organization. Am Nat 111:1119-1144

Connell JH, Sousa WP (1983) On the evidence needed to judge ecological stability or persistence. Am Nat 121: 789-824

Connell JH, Hughes TP, Wallace CC (1997) A 30-year study of coral abundance, recruitment, and disturbance at several scales in space and time. Ecol Monogr 67:461-488

Crabbe MJC (2009) Scleractinian coral population size structures and growth rates indicate coral resilience on the fringing reefs of North Jamaica. Mar Environ Res 67: $189-198$

Davis GE (1982) A century of natural change in coral distribution in the Dry Tortugas: a comparison of reef maps from 1881 and 1976. Bull Mar Sci 32:608-623

> Diaz-Pulido G, McCook LJ, Dove S, Berkelmans J and others (2009) Doom and boom on a resilient reef: climate change, algal overgrowth and coral recovery. PLoS ONE 4:e5239

Done TJ (1992) Phase shifts in coral reef communities and their ecological significance. Hydrobiologia 247:121-132

> Done TJ, Dayton PK, Dayton AE, Steger R (1991) Regional and local variability in recovery of shallow coral communities: Moorea, French Polynesia and central Great Barrier Reef. Coral Reefs 9:183-192

Eakin CM (1996) Where have all the carbonates gone? A model comparison of calcium carbonate budgets before and after the 1982-1983 El Niño. Coral Reefs 15:109-119

Eakin CM (2001) A tale of two ENSO events: carbonate budgets and the influence of two warming disturbances and intervening variability, Uva Island, Panama. Bull Mar Sci 69:171-186

Edmunds PJ, Carpenter RC (2001) Recovery of Diadema antillarum reduces macroalgal cover and increases abundance of juvenile corals on a Caribbean reef. Proc Natl Acad Sci USA 98:5067-5071

Edwards AJ, Gomez ED (2007) Reef restoration concepts and guidelines: making sensible management choices in the face of uncertainty. Coral Reef Targeted Research \& Capacity Building for Management Programme, St Lucia, Australia

Elmhirst T, Connolly SR, Hughes TP (2009) Connectivity, regime shifts and the resilience of coral reefs. Coral Reefs 28:949-957

Elmqvist T, Folke C, Nyström M, Peterson G, Bengtsson J, Walker B, Norberg J (2003) Response diversity, ecosystem change, and resilience. Front Ecol Environ 1:488-494

Emlen JM (1977) Ecology: an evolutionary approach. Addison-Wesley, Reading, MA

Emslie MJ, Cheal AJ, Sweatman H, Delean S (2008) Recovery from disturbance of coral and reef fish communities on the Great Barrier Reef, Australia. Mar Ecol Prog Ser 371: $177-190$

Endean R, Stablum W (1973) The apparent extent of recovery of reefs of Australia's Great Barrier Reef devastated by the crown-of-thorns starfish. Atoll Res Bull 168:1-41

Fong P, Smith TB, Wartian MJ (2006) Epiphytic cyanobacteria maintain shifts to macroalgal dominance on coral reefs following ENSO disturbance. Ecology 87:1162-1168

Graham MH, Dayton PK (2002) On the evolution of ecological ideas: paradigms and scientific progress. Ecology 83: $1481-1489$

Greenaway AM, Gordon-Smith D (2006) The effects of rainfall on the distribution of inorganic nitrogen and phos- 
phorus in Discovery Bay, Jamaica. Limnol Oceanogr 51: $2206-2220$

Greenstein BJ, Pandolfi JM (2008) Escaping the heat: range shifts of reef coral taxa in coastal Western Australia. Glob Change Biol 14:513-528

Grimm V, Wissel C (1997) Babel, or the ecological stability discussions: an inventory and analysis of terminology and a guide for avoiding confusion. Oecologia 109:323-334

- Halpern BS, Silliman BR, Olden JD, Bruno JP, Bertness MD (2007) Incorporating positive interactions in aquatic restoration and conservation. Front Ecol Environ 5:153-160

Hardt MJ (2008) Lessons from the past: the collapse of Jamaican coral reefs. Fish Fish 10:1-16

Hare SR, Mantua NJ (2000) Empirical evidence for North Pacific regime shifts in 1977 and 1989. Prog Oceanogr 47: 103-145

> Hatcher BG (1984) A maritime accident provides evidence for alternate stable states in benthic communities on coral reefs. Coral Reefs 3:199-204

Hatcher BG (1992) Kelp beds on coral reefs: alternate stable benthic communities co-exist in high latitude reef systems (abstract). Proc 7th Int Coral Reef Symp, Guam 2:1239

Hawkins JP, Roberts CM (2004) Effects of artisanal fishing on Caribbean coral reefs. Conserv Biol 18:215-226

Hilborn R (2004) Ecosystem-based fisheries management: the carrot or the stick? Mar Ecol Prog Ser 274:275-278

Holling CS (1973) Resilience and stability of ecological systems. Annu Rev Ecol Syst 4:1-23

Hughes TP (1994) Catastrophes, phase shifts, and large-scale degradation of a Caribbean coral reef. Science 265: 1547-1551

Hughes TP, Bellwood DR, Folke C, Steneck RS, Wilson J (2005) New paradigms for supporting the resilience of marine ecosystems. Trends Ecol Evol 20:380-386

Hunter CL, Evans CW (1995) Coral reefs in Kaneohe Bay, Hawaii: two centuries of Western influence and two decades of data. Bull Mar Sci 57:501-515

Idjadi JA, Lee SC, Bruno JF, Precht WF, Allen-Requa L, Edmunds PJ (2006) Rapid phase-shift reversal on a Jamaican coral reef. Coral Reefs 25:209-211

Idjadi JA, Haring RN, Precht WF (2010) Recovery of the sea urchin Diadema antillarum promotes scleractinian coral growth and survivorship on shallow Jamaican reefs. Mar Ecol Prog Ser 403:91-100

Ivany LC, Brett CE, Wall HLB, Wall PD, Handley JC (2009) Relative taxonomic and ecologic stability in Devonian marine faunas of New York State: a test of coordinated stasis. Paleobiology 35:499-524

Jackson JBC, Johnson KG (2000) Life in the last few million years. Paleobiology 26(Suppl):221-235

Jackson JBC, Kirby MX, Berger WH, Bjorndal KA and others (2001) Historical overfishing and the recent collapse of coastal ecosystems. Science 293:629-638

Kaiser MJ, Attrill MJ, Jennings S, Thomas DN and others (2005) Marine ecology: processes, systems, impacts. Oxford University Press, Oxford, UK

Knowlton N (1992) Thresholds and multiple stable states in coral reef community dynamics. Am Zool 32:674-682

Knowlton N (2001) The future of coral reefs. Proc Natl Acad Sci USA 98:5419-5425

Knowlton N (2004) Multiple 'stable' states and the conservation of marine ecosystems. Prog Oceanogr 60:387-396

Knowlton N (2006) Coral reef coda: what can we hope for? In: Côté IM, Reynolds JD (eds) Coral reef conservation. Cambridge University Press, Cambridge, UK, p 538-549

Lessios HA (1988) Mass mortality of Diadema antillarum in the Caribbean: what have we learned? Annu Rev Ecol Syst 19:371-393
Levins R (1968) Evolution in changing environments. Princeton University Press, Princeton, NJ

Lewontin RC (1969) The meaning of stability. In: Woodwell GM, Smith HH (eds) Diversity and stability in ecological systems, Vol 22. Brookhaven National Laboratory, Upton, NY, p 13-24

Liddell WD, Ohlhorst SL (1992) Ten years of disturbance and change on a Jamaican fringing reef. Proc 7 th Int Coral Reef Symp, Guam 1:144-150

Lighty RG (1980) Fleshy-algal domination of a modern Bahamian barrier reef: example of an alternative climax reef community (abstract). Proc 4th Int Coral Reef Symp, Manila 1:722

Lighty RG, Macintyre IG, Stuckenrath R (1978) Submerged early Holocene barrier reef, south-east Florida shelf. Nature 276:59-60

Lotka AJ (1956) Elements of mathematical biology. Dover Publications, New York, NY

Loya Y (2004) The coral reefs of Eilat-past, present and future: three decades of coral community structure studies. In: Rosenberg E, Loya Y (eds) Coral health and disease. Springer-Verlag, Berlin, p 1-34

Macia S, Robinson MP, Nalevanko A (2007) Experimental dispersal of recovering Diadema antillarum increases grazing intensity and reduces macroalgal abundance on a coral reef. Mar Ecol Prog Ser 348:173-182

Maragos J, Evans C, Holthus P (1985) Reef corals in Kaneohe Bay six years before and after termination of sewage discharges (Oahu, Hawaiian Archipelago). Proc 5th Int Coral Reef Congr, Tahiti, 4:189-194

May RM (1977) Thresholds and breakpoints in ecosystems with a multiplicity of stable states. Nature 269:471-477

McManus JW, Polsenberg JF (2004) Coral-algal phase shifts on coral reefs: ecological and environmental aspects. Prog Oceanogr 60:263-279

Mumby PJ (2006) The impact of exploiting grazers (Scaridae) on the dynamics of Caribbean coral reefs. Ecol Appl 16: $747-769$

Mumby PJ (2009) Phase shifts and the stability of macroalgal communities on Caribbean coral reefs. Coral Reefs 28: 761-773

Mumby PJ, Harborne AR (2010) Marine reserves enhance the recovery of corals on Caribbean reefs. PLoS ONE 5:e8657

Mumby PJ, Hastings A, Edwards HJ (2007a) Thresholds and the resilience of Caribbean coral reefs. Nature 450:98-101

Mumby PJ, Harborne AR, Williams J, Kappel CV and others (2007b) Trophic cascade facilitates coral recruitment in a marine reserve. Proc Natl Acad Sci USA 104:8362-8367

Ninio R, Meekan M, Done T, Sweatman H (2000) Temporal patterns in coral assemblages on the Great Barrier Reef from local to large spatial scales. Mar Ecol Prog Ser 194: $65-74$

Norström AV, Nyström M, Lokrantz J, Folke C (2009) Alternative states on coral reefs: beyond coral-macroalgal phase shifts. Mar Ecol Prog Ser 376:295-306

> Nyström M, Folke C, Moberg F (2000) Coral reef disturbance and resilience in a human-dominated environment. Trends Ecol Evol 15:413-417

Nyström M, Graham NAJ, Lokrantz J, Norström AV (2008) Capturing the cornerstones of coral reef resilience: linking theory to practice. Coral Reefs 27:795-809

Paine RT (1977) Controlled manipulations in the marine intertidal zone and their contributions to ecological theory. In: Goulden CE (ed) The changing scenes in the natural sciences, 1776-1976. Academy of Natural Sciences, Philadelphia, PA, p 245-270

Palumbi SR, McLeod KL, Grünbaum D (2008) Ecosystems in action: lessons from marine ecology about recovery, resis- 
tance, and reversibility. Bioscience 58:33-42

Pandolfi JM, Bradbury RH, Sala E, Hughes TP and others (2003) Global trajectories of the long-term decline of coral reef ecosystems. Science 301:955-958

Peterson CH (1984) Does a rigorous criterion for environmental identity preclude the existence of multiple stable points? Am Nat 124:127-133

Petraitis PS, Dudgeon SR (2004) Detection of alternative stable states in marine communities. J Exp Mar Biol Ecol 300: 343-371

$>$ Petraitis PS, Dudgeon SR (2005) Divergent succession and implications for alternative states on rocky intertidal shores. J Exp Mar Biol Ecol 326:14-26

Petraitis PS, Hoffman CA (2010) Multiple stable states and relationship between thresholds in processes and states. Mar Ecol Prog Ser 413:189-200

Petraitis PS, Latham R (1999) The importance of scale in testing the origins of alternative community states. Ecology 80:429-442

Petraitis PS, Latham RE, Niesenbaum RA (1989) The maintenance of species diversity by disturbance. Q Rev Biol 64: 393-418

Petraitis PS, Methratta ET, Rhile EC, Vidargas NA, Dudgeon SR (2009) Experimental confirmation of multiple community states in a marine ecosystem. Oecologia 161:139-148

Power ME, Tilman D, Estes JA, Menge BA and others (1996) Challenges in the quest for keystones. Bioscience 46: 609-620

Precht WF, Aronson RB (2004) Climate flickers and range shifts of reef corals. Front Ecol Environ 2:307-314

Precht WF, Aronson RB (2006a) Rapid range expansion of reef corals in response to climatic warming (abstract). Geol Soc America Abstr Progr 38:535

Precht WF, Aronson RB (2006b) Death and resurrection of Caribbean coral reefs: a palaeoecological approach. In: Côté IM, Reynolds JD (eds) Coral reef conservation. Cambridge University Press, Cambridge, UK, p 40-77

Precht WF, Aronson RB, Swanson DW (2001) Improving scientific decision-making in the restoration of shipgrounding sites on coral reefs. Bull Mar Sci 69:1001-1012

Precht WF, Aronson RB, Moody RM, Kaufman L (2010) Changing patterns of microhabitat utilization by the threespot damselfish, Stegastes planifrons, on Caribbean reefs. PLoS ONE 5:e10835

Quinn NJ, Kojis BL (2008) The recent collapse of a rapid phase-shift reversal on a Jamaican north coast coral reef after the 2005 bleaching event. Rev Biol Trop 56(Suppl1): $149-159$

Ricklefs RE (1979) Ecology, 2nd edn. Chiron, New York

> Riegl B, Bruckner A, Coles SL, Renaud P, Dodge RE (2009) Coral reefs: threats and conservation in an era of global change. Ann N Y Acad Sci 1162:136-186

Rogers CS, Miller J (2006) Permanent 'phase shifts' or reversible declines in coral cover? Lack of recovery of two coral reefs in St. John, US Virgin Islands. Mar Ecol Prog Ser 306:103-114

Romme WH (1982) Fire and landscape diversity in subalpine forests of Yellowstone National Park. Ecol Monogr 52: 199-221

Romme WH, Despain DG (1989) Historical perspective on the Yellowstone fires of 1988. Bioscience 39:695-699

Romme WH, Turner MG (2004) Ten years after the 1988 Yellowstone fires: is restoration needed? In: Wallace LL (ed) After the fires: the ecology of change in Yellowstone National Park. Yale University Press, New Haven, CT, p 318-361

Sammarco PW (1980) Diadema and its relationship to coral spat mortality: grazing, competition, and biological disturbance. J Exp Mar Biol Ecol 45:245-272

Sammarco PM (1982a) Effects of grazing by Diadema antillarum Philippi (Echinodermata: Echinoidea) on algal diversity and community structure. J Exp Mar Biol Ecol 65: 83-105

Sammarco PW (1982b) Echinoid grazing as a structuring force in coral communities: whole-reef manipulations. J Exp Mar Biol Ecol 61:31-55

> Scheffer M, Carpenter SR (2003) Catastrophic regime shifts in ecosystems: linking theory to observation. Trends Ecol Evol 18:648-656

Scheffer M, Carpenter S, Foley JA, Folke C, Walker B (2001) Catastrophic shifts in ecosystems. Nature 413:591-596

Schröder A, Perrson L, DeRoos AM (2005) Direct experimental evidence for alternative stable states: a review. Oikos 110:3-19

Schroeder RE, Green AL, DeMartini EE, Kenyon JC (2008) Long-term effects of a ship-grounding on coral reef fish assemblages at Rose Atoll, American Samoa. Bull Mar Sci 82:345-364

> Schutte VGW, Selig ER, Bruno JF (2010) Regional spatiotemporal trends in Caribbean coral reef benthic communities. Mar Ecol Prog Ser 402:115-122

Simberloff D (1998) Flagships, umbrellas, and keystones: is single species management passé in the landscape era? Biol Conserv 83:247-257

Smale DA, Kendrick GA, Waddington KI, Van Niel KP, Meeuwig JJ, Harvey ES (2010) Benthic assemblage composition on subtidal reefs along a latitudinal gradient in Western Australia. Estuar Coast Shelf Sci 86:83-92

> Sousa WP, Connell JH (1985) Further comments on the evidence for multiple stable points in natural communities. Am Nat 125:612-615

> Stimson J, Conklin E (2008) Potential reversal of a phase shift: the rapid decrease in the cover of the invasive green macroalga Dictyosphaeria cavernosa Forsskål on coral reefs in Kāne'ohe Bay, Oahu, Hawai'i. Coral Reefs 27: $717-726$

Stoddart DR (1963) Effects of Hurricane Hattie on the British Honduras reefs and cays, October 30-31, 1961. Atoll Res Bull 95:1-142

Stoddart DR (1969) Post-hurricane changes on the British Honduras reefs and cays: re-survey of 1965. Atoll Res Bull 131:1-25

Stoddart DR (1974) Post-hurricane changes on the British Honduras reefs: re-survey of 1972. Proc 2nd Int Coral Reef Symp, Brisbane 2:473-483

> Turner MG, Romme WH, Tinker DB (2003) Surprises and lessons from the 1988 Yellowstone fires. Front Ecol Environ 1:351-358

> Watson M, Munro JL (2004) Settlement and recruitment of coral reef fishes in moderately exploited and overexploited Caribbean ecosystems: implications for marine protected areas. Fish Res 69:415-425

Webber M, Edwards-Myers E, Campbell C, Webber D (2005) Phytoplankton and zooplankton as indicators of water quality in Discovery Bay, Jamaica. Hydrobiologia 545: $177-193$

Woodley JD (1999) Sea urchins exert top-down control on Jamaican coral reefs. Coral Reefs 18:192

Woodley JD, Sary Z (2000) Development of a locally managed fisheries reserve at Discovery Bay, Jamaica. Proc 9th Int Coral Reef Symp, Bali 2:627-634

> Work TM, Aeby GS, Maragos JE (2008) Phase shift from a coral to a corallimorph-dominated reef associated with a shipwreck on Palmyra Atoll. PLoS ONE 3:e2989 